\title{
Umbilical Endometriosis
}

*Ayida A. Al-Khalili ${ }^{1,2}$ and Robin Billick ${ }^{3}$

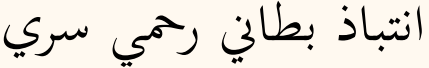

عايدة عبد الله الخليلية و روين بيليك

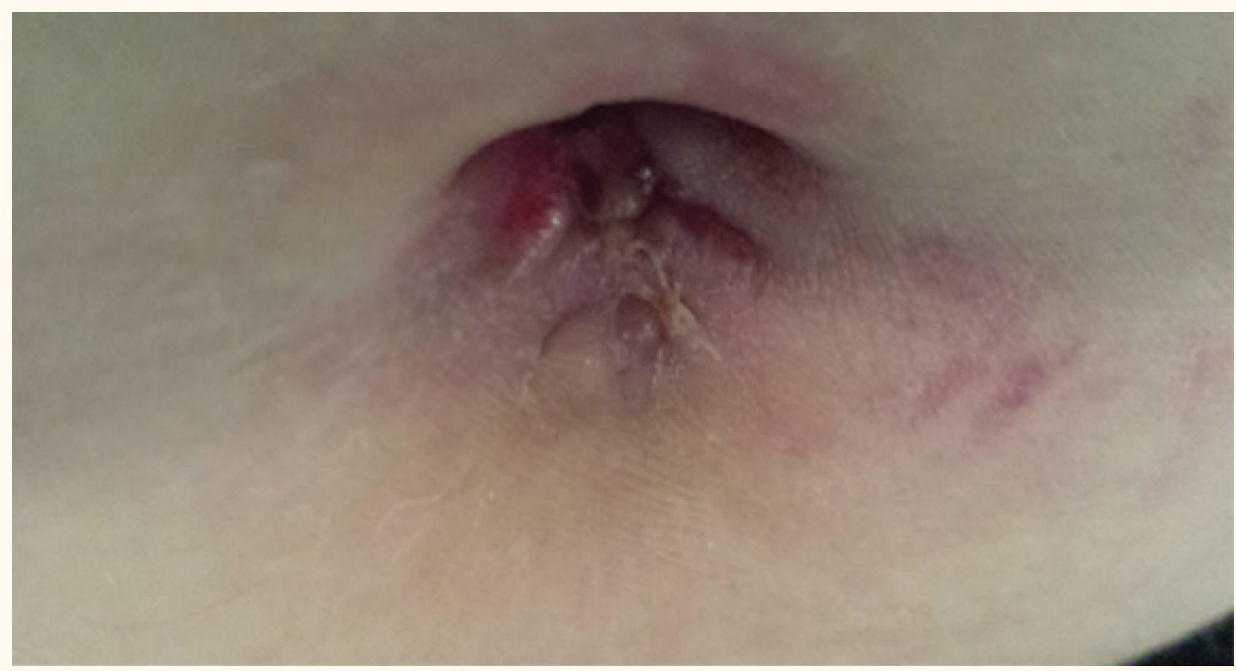

Figure 1: Multiple erythematous papules on the lower umbilical area of a 43-year-old nulliparous woman.

A 43-YEAR-OLD NULLIPAROUS WOMAN PRESENTED to a dermatology clinic in Montreal, Quebec, Canada, in 2015 with swelling and pain in the umbilical area which worsened and occasionally bled during menstruation. The onset of these symptoms coincided with the discontinuation of oral contraceptive pills, which she had been taking for the last seven years. The patient complained of dysmenorrhoea and had no history of abdominal or pelvic surgeries. Upon clinical examination, multiple ill-defined bluish erythematous papules were noted in and surrounding the umbilicus [Figure 1]. A skin biopsy showed glandular proliferation with hemosiderin deposition and myometrial stroma, consistent with a diagnosis of endometriosis [Figure 2]. A gynaecological evaluation revealed an ovarian cyst. She was treated with progestin which relieved the dysmenorrhoea and resulted in the regression of both the ovarian cyst and her umbilical symptoms. As most of the remaining umbilical nodules were small and remained asymptomatic, the patient did not wish to have them surgically removed.

\section{Comment}

Endometriosis refers to the presence of endometrial tissue outside of the uterine cavity. Extrapelvic or extragenital endometriosis has been described in several anatomical locations, including the skin, brain, lungs, gastrointestinal tract, urinary system and musculature. ${ }^{1}$ While umbilical endometriosis-also known as Villar's nodule-is a rare site for endometriosis, it is the most common form of cutaneous endometriosis. ${ }^{2}$ There are many theories to explain the pathophysiology of umbilical endometriosis, including migration via the vascular or lymphatic vessels, metaplastic transformation and iatrogenic implants. ${ }^{2}$

Umbilical endometriosis is classified as primary if it occurs spontaneously or secondary if it results from iatrogenically-seeded endometrial implants following various surgical procedures, with the latter being more common. ${ }^{2,3}$ Umbilical endometriosis constitutes $3.2-40 \%$ of all extragenital endometrioses. ${ }^{2}$ Symptoms include umbilical masses with swelling and pain 


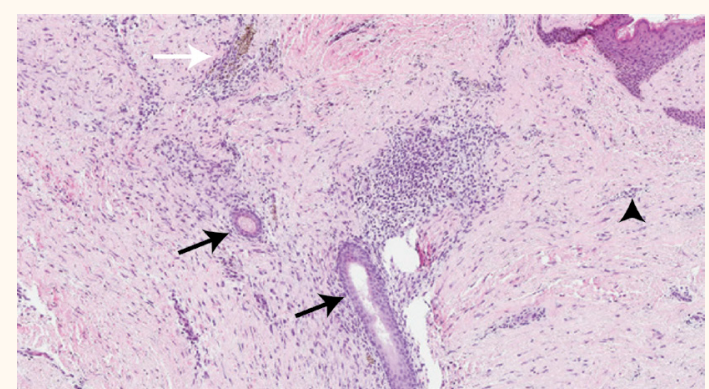

Figure 2: Haematoxylin and eosin stain at x40 magnification showing glandular proliferation (black arrows) with hemosiderin deposition (white arrow) and myometrial stroma (arrowhead). These features were deemed indicative of umbilical endometriosis.

during menstruation and, to a lesser extent, bleeding. ${ }^{2}$ The differential diagnosis of the condition includes both benign and malignant tumours, such as primary and metastatic neoplasms, polyps, granulomas and keloids. ${ }^{1}$ However, the risk of malignant transformation is minimal. ${ }^{3}$

Currently, there is as yet no consensus on the optimal management strategy for umbilical endometriosis; therefore, treatment should be personalised to each patient and will depend on the severity of symptoms and the coexistence of pelvic endometriosis. ${ }^{4}$ Suggested therapeutic options include various surgical procedures and treatment with hormonal therapy or danazol. ${ }^{2,4,5}$

\section{References}

1. Davis AC, Goldberg JM. Extrapelvic endometriosis. Semin Reprod Med 2017; 35:98-101. doi: 10.1055/s-0036-1597122.

2. Victory R, Diamond MP, Johns DA. Villar's nodule: A case report and systematic literature review of endometriosis externa of the umbilicus. J Minim Invasive Gynecol 2007; 14:23-32. doi: 10.1016/j.jmig.2006.07.014.

3. Calagna G, Perino A, Chianetta D, Vinti D, Triolo MM, Rimi C, et al. Primary umbilical endometrioma: Analyzing the pathogenesis of endometriosis from an unusual localization. Taiwan J Obstet Gynecol 2015; 54:306-12. doi: 10.1016/j. tjog.2014.03.011.

4. Mechsner S, Bartley J, Infanger M, Loddenkemper C, Herbel J, Ebert AD. Clinical management and immunohistochemical analysis of umbilical endometriosis. Arch Gynecol Obstet 2009; 280:235-42. doi: 10.1007/s00404-008-0900-4.

5. Fancellu A, Pinna A, Manca A, Capobianco G, Porcu A. Primary umbilical endometriosis: Case report and discussion on management options. Int J Surg Case Rep 2013; 4:1145-8. doi: 10.1016/j.ijscr.2013.11.001. 